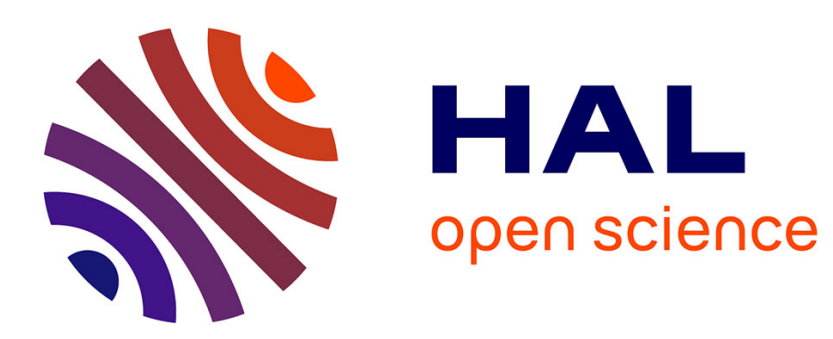

\title{
Plasma diagnostics in gas metal arc welding by optical emission spectroscopy
}

\author{
Flavien Valensi, S Pellerin, A Boutaghane, K Dzierzega, S Zielinska, N
}

Pellerin, F Briand

\section{- To cite this version:}

Flavien Valensi, S Pellerin, A Boutaghane, K Dzierzega, S Zielinska, et al.. Plasma diagnostics in gas metal arc welding by optical emission spectroscopy. Journal of Physics D: Applied Physics, 2010, 43, pp.434002. 10.1088/0022-3727/43/43/434002 . hal-00569730

\section{HAL Id: hal-00569730 \\ https://hal.science/hal-00569730}

Submitted on 25 Feb 2011

HAL is a multi-disciplinary open access archive for the deposit and dissemination of scientific research documents, whether they are published or not. The documents may come from teaching and research institutions in France or abroad, or from public or private research centers.
L'archive ouverte pluridisciplinaire HAL, est destinée au dépôt et à la diffusion de documents scientifiques de niveau recherche, publiés ou non, émanant des établissements d'enseignement et de recherche français ou étrangers, des laboratoires publics ou privés. 


\title{
Plasma diagnostic in gas metal arc welding by optical emission spectroscopy
}

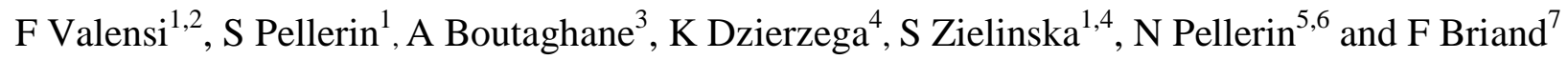 \\ ${ }^{1}$ GREMI, Université d'Orléans (Site de Bourges) / CNRS, BP 4043, 18028 Bourges cedex, France \\ ${ }^{2}$ LAPLACE-AEPPT, Université Paul Sabatier/CNRS, 31062 Toulouse cedex 9, France \\ ${ }^{3}$ Université des Sciences et de la Technologie Houari Boumediene, Alger, Algérie \\ ${ }^{4}$ Marian Smoluchowski Institute of Physics, Jagellonian University, Krakow, Poland \\ ${ }^{5}$ CNRS, UPR3079 CEMHTI, 1D av. de la Recherche Scientifique, 45071 Orléans cedex 2, France \\ ${ }^{6}$ Université d'Orléans, Faculté des Sciences (Site de Bourges), BP 4043, 18028 Bourges cedex, France \\ ${ }^{7}$ CTAS-Air Liquide Welding, Saint Ouen l'Aumône, 95315 Cergy-Pontoise cedex, France
}

$\begin{array}{ll}\text { E-mail adresses : } & \begin{array}{l}\text { flavien.valensi@laplace.univ-tsle.fr } \\ \text { stephane.pellerin@univ-orleans.fr }\end{array} \\ & \begin{array}{l}\text { aboutaghane@yahoo.fr } \\ \text { krzycho@ @etmail.if.uj.edu.pl }\end{array} \\ & \begin{array}{l}\text { sylwia.zielinska@airliquide.com } \\ \text { nadia.pellerin@univ-orleans.fr }\end{array} \\ & \text { francis.briand@airliquide.com }\end{array}$

Abstract:
emission spectroscopy and high-speed imaging. The concentration and repartition of iron
vapours are measured and correlated to the plasma and electrode geometric configuration.
Plasma temperatures and electron densities were also measured for each studied position in
the plasma. The temperatures are calculated using two different methods, allowing
validation of the local thermodynamic equilibrium state of the plasma. The results show a
maximum temperature of $12500 \mathrm{~K}$ on the arc upper part, away from the arc axis. The iron
concentration reaches a maximum of $0.3 \%$ close to the anode and strongly decreases along
both the vertical and the radial directions.
The plasma thermophysical properties, calculated from this plasma composition, are then
discussed regarding the metal transfer mode.

Keywords: $\quad$ GMAW, Argon, optical emission spectroscopy, LTE, ratio Fe/Ar, metal vapours

PAC number : $\quad$ 52.50.Dg, 52.50.Nr, 52.70.Kz, 52.75.Hn, 52.77.Fv

Submitted to : Journal of Physics D: Applied Physics for the 'Metal vapour' cluster issue 


\section{Introduction}

Arc welding is a widely used process for joining metals in a wide range of applications. In gas metal arc welding (GMAW), an arc burns between a consumable anode wire and the workpiece, constituting the cathode. The melted metal is shielded from the atmosphere using an inert or an active gas. The process has been widely investigated since its firsts developments [1, 2], but all phenomenon governing metal transfer and its dependence on plasma parameters are not yet explained. The melting of the anode leads to a strong vaporisation and plasma enrichment in metal vapours, mainly iron. Even in the metal inert gas (MIG) process, the plasma composition is more complex than in tungsten inert gas welding process. The arc is also less stable due to the instabilities caused by the melted metal droplets detaching from the anode.

Depending on the welding conditions, mainly current intensity and shielding gas used, metal transfer can occur in various modes. The most stable one is called spray arc and leads to the best quality welds. It is characterized by a tapering of the melted anode wire extremity and a cone shaped arc. The droplet mean size is about one half of the wire diameter and the detachment frequency is several hundreds of Hertz. Under pure argon, this transfer mode occurs for currents greater than 250 amperes [3].

Plasma models are developed for understanding and predicting welding arc behaviour, but in order to get meaningful results, many parameters have to be considered.

Arc stability and metal transfer quality is sensitive to droplets detachment from the anode wire extremity. The two opposite forces governing this phenomenon are the surface tension and the electromagnetic force. The last one, causing the droplets detachment, depends on the current line geometry in the droplet and the plasma, especially around the melting anode wire. As the presence of metal vapours strongly increases the plasma electrical conductivity, information on their repartition are of major importance in determining electromagnetic forces.

The plasma energy balance is also affected by the presence of metal vapours. They increase the thermal losses due to their greater thermal conductivity and their stronger emissivity. Previous results [4] have showed that the electron temperature decreased close to the axis of the arc column, which is not predicted by models neglecting the influence of the metal vapours or assuming their repartition as homogeneous $[5,6]$.

In this work, experimental measurements of the plasma main parameters are presented. The iron vapours concentration and their spatial repartition are obtained from iron and argon lines, as well as the temperature and the electron density. The spectroscopic data are compared to images obtained with a high-speed camera, which provided information on the temporal evolution of the plasma and electrodes configuration. The aim of this study is to provide experimental reference data for plasma temperature, electron density and composition for plasma modelling.

\section{Spectroscopic diagnostic}

The determination of the proportion of iron vapours in argon can be done by measuring the emissivity of lines for both elements, provided the plasma temperature is known and the Local Thermodynamical Equilibrium (LTE) hypothesis is validated. Then, the first step is to calculate the temperature. In order to validate the LTE hypothesis two methods are used. The first method needs no hypothesis on the plasma equilibrium state, and allows also the electron density determination. The second method is used to give the excitation temperatures. When the two temperatures match, the LTE state of the plasma can be assumed. For the plasma parts where the LTE is valid, the iron vapours concentration can then be calculated.

\subsection{Temperature measurement based on Stark broadening}

The basis of this method has initially been developed by Sola et al. [7, 8]. In the present work, we used the same lines as in what we presented in [4]. The Stark broadening of the iron line at $538.3 \mathrm{~nm}$ and the argon line at $696.5 \mathrm{~nm}$ are measured under the same experimental conditions, after checking the reproducibility of the experiments. The dependence on electron temperature and electron density for the iron line $[9,10]$ is given by: 


$$
\Delta \lambda_{S}^{F e}=0.2648 \cdot \frac{N_{e}}{10^{23}} \cdot\left(\frac{T_{e}}{13000}\right)^{1.6700}
$$

For the $696.5 \mathrm{~nm}$ argon line dependence [11], the relation writes as:

$$
\Delta \lambda_{S}^{A r}=0.0814 \cdot \frac{N_{e}}{10^{23}} \cdot\left(\frac{T_{e}}{13000}\right)^{0.3685}
$$

The measure of the Stark broadening, of both the iron line and the argon line, allows equations $(1,2)$ to be solved for electronic temperature $T_{e}$ and electronic density $N_{e}$.

\subsection{Excitation temperature measurement: the Boltzmann plot method}

The excitation temperature can be easily calculated using the Boltzmann plot method. However, unlike the one based on Stark broadening, the Boltzmann plot method needs the LTE hypothesis validity. It is widely used in plasma diagnostic, using for instance Ar I lines on an electric arc [12].

The emissivity of the transition from a level $k$ to a level $i$ is given by:

$$
\varepsilon_{k i}=N_{k} A_{k i} \frac{h v_{k i}}{4 \pi}=N_{k} A_{k i} \frac{h c}{4 \pi \lambda_{k i}}
$$

$N_{k}=N_{k}\left(T_{e}\right)$ is the $k$ level population, $A_{k i}, v_{k}$ and $\lambda_{k i}$ are the probability, in $\mathrm{s}^{-1}$, the frequency, in $\mathrm{s}^{-1}$ and the wavelength in meter, respectively.

When the Boltzmann equilibrium exists, the $N_{k}$ population follows the Boltzmann Law and the emission coefficient becomes:

$$
\varepsilon_{\mathrm{ki}}\left(\mathrm{T}_{\mathrm{e}}\right)=\mathrm{K}\left(\mathrm{T}_{\mathrm{e}}\right) \mathrm{A}_{\mathrm{ki}} v_{\mathrm{ki}} \mathrm{g}_{\mathrm{k}} \exp \left(-\frac{\mathrm{E}_{\mathrm{k}}}{\mathrm{kT} \mathrm{T}_{\mathrm{e}}}\right)
$$

This can be written as:

$$
y \equiv \ln \left(\frac{\varepsilon_{k i}}{A_{k i} \nu_{k i} g_{k}}\right)=\ln K-\frac{E_{k}}{k T_{e}}
$$

\begin{tabular}{|c|c|c|c|c|c|c|}
\hline 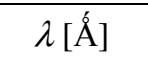 & Configurations & Terms & $E_{k}[\mathrm{~cm}-1]$ & $g_{k}$ & $A_{k i}\left[10^{8} \mathrm{~s}^{-1}\right]$ & Accuracy \\
\hline 5383.369 & $3 d^{7} 4 p-3 d^{7} 4 d$ & $\mathrm{z}^{5} \mathrm{G}^{\circ}-\mathrm{e}^{5} \mathrm{H}$ & 53352.98 & 13 & 0.56 & $\mathrm{C}^{+}$ \\
\hline 5393.167 & $3 d^{6} 4 s 4 p-3 d^{6} 4 s 5 s$ & $z^{5} D-e^{5} D$ & 44677.004 & 9 & 0.031 & $\mathrm{C}^{+}$ \\
\hline 5397.127 & $3 d^{7} 4 s-3 d^{6} 4 s 4 p$ & $a^{5} F-z^{5} D$ & 25899.987 & 9 & 0.00259 & $\mathrm{~B}^{+}$ \\
\hline 6965.431 & $4 s-4 p^{\prime}$ & {$\left[\begin{array}{ll}1 & 1 / 2\end{array}\right]^{\circ}-\left[\begin{array}{l}1 / 2 \\
0\end{array}\right]$} & 107496.4166 & 3 & 0.0639 & $\mathrm{C}$ \\
\hline
\end{tabular}

By plotting the measured emissivity for lines with different energies $E_{k}$, the experimental points should be aligned with a slope proportional to the inverse of temperature. The three iron lines at 538.3, 539.3 and $539.7 \mathrm{~nm}$ have been are selected. The details of the spectroscopic parameters are given in Table 1.

Table 1. Spectroscopic data used for diagnostic [13, 14] [Accuracy: A $\leq 5 \%$; B $\leq 10 \%$; C $\leq 25 \%$ ].

The three lines, providing a wide energy range, can be recorded during the same experiment, which reduced the uncertainty associated with calibration. However, the accuracy of some line spectroscopic data remains low.

\subsection{Metal vapour concentration calculations}

When the plasma is in LTE, the emission coefficient of a line with a wavelength $\lambda_{n m}$ writes as:

$$
\varepsilon_{n m}=\frac{h c}{4 \pi \lambda_{n m}} \cdot g_{n} \cdot A_{n m} \cdot \frac{N(T)}{U(T)} \cdot \exp \left(\frac{-E_{n}}{k T}\right)
$$


The emissivity of the argon line and the $538.3 \mathrm{~nm}$ iron line are measured under the same experimental condition. The emissivity is obtained after calibration of the optical setup with a tungsten lamp. Equation 6 is applied to both lines and yields to the ratio expression as:

$$
\frac{N_{F e}(T)}{N_{A r}(T)}=\frac{\lambda_{F e}}{\lambda_{A r}} \cdot \frac{g_{A r}}{g_{F e}} \cdot \frac{A_{A r}}{A_{F e}} \cdot \frac{U_{F e}(T)}{U_{A r}(T)} \cdot \frac{\varepsilon_{F e}(T)}{\varepsilon_{A r}(T)} \cdot \exp \left(-\frac{E_{A r}-E_{F e}}{k T}\right)
$$

The partition function for argon is taken equals to 1 , which is acceptable if the temperature is lower than $15000 \mathrm{~K}$ [15]. The partition function for Iron is fitted from the results available in literature [16, 17] by using a polynomial function:

$$
U_{F e}(T)=2.55743-2.23674 \times 10^{-4} T+4.11403 \times 10^{-8} T^{2}-1.89172 \times 10^{-12} T^{3}+3.24343 \times 10^{-17} T^{4}
$$

\section{Experimental setup}

The experiments were carried out by using the setup presented in Figure 1. A SAFMIG 480 TRS PLUS generator with a solid consumable wire anode of mild steel (AWS A5.17) with a diameter of $1.2 \mathrm{~mm}$ was used to perform welding experiments. The shielding gas was pure argon with a flow of $20 \mathrm{~L} \mathrm{mn}^{-1}$ and the current was set at 330 amperes. The distance between the contact tip and the metal plate constituting the workpiece was set to $20 \mathrm{~mm}$ and the wire feed speed to $9 \mathrm{~m} . \mathrm{mn}^{-1}$, which provides an arc length of about $10 \mathrm{~mm}$. This distance is slightly greater than what is commonly used in real welding, however, we cheeked that this arc length leads to no major modification of the process. In order to get a steady plasma position, for optics alignment, the torch was fixed and the workpiece was placed on a moving table driven by a step motor.

The spectroscopic measurements were made using an Ebert-type spectrograph with a reciprocal dispersion of $0.2 \mathrm{~nm} \mathrm{~mm}^{-1}$. The spectra were recorded with a gated two-dimensional intensified charge-coupled device (ICCD) with a spectral resolution of $0.004 \mathrm{~nm}$ at $539 \mathrm{~nm}$ and $0.003 \mathrm{~nm}$ at $696.5 \mathrm{~nm}$. Spectra were recorded with an exposure time of $50 \mathrm{~ms}$ at a frequency of three acquisitions per second. In each case a dozen of spectra were recorded.

The light coming from the plasma was brought to the spectrograph entrance slit through a system of concave and flat mirrors with an optical magnification of 0.4. This led to a spatial resolution of $62 \mu \mathrm{m}$ along the direction of the spectrometer vertical slit. A Dove prism was used to rotate the image by $90^{\circ}$ and get radial profiles for the chosen plasma slice.

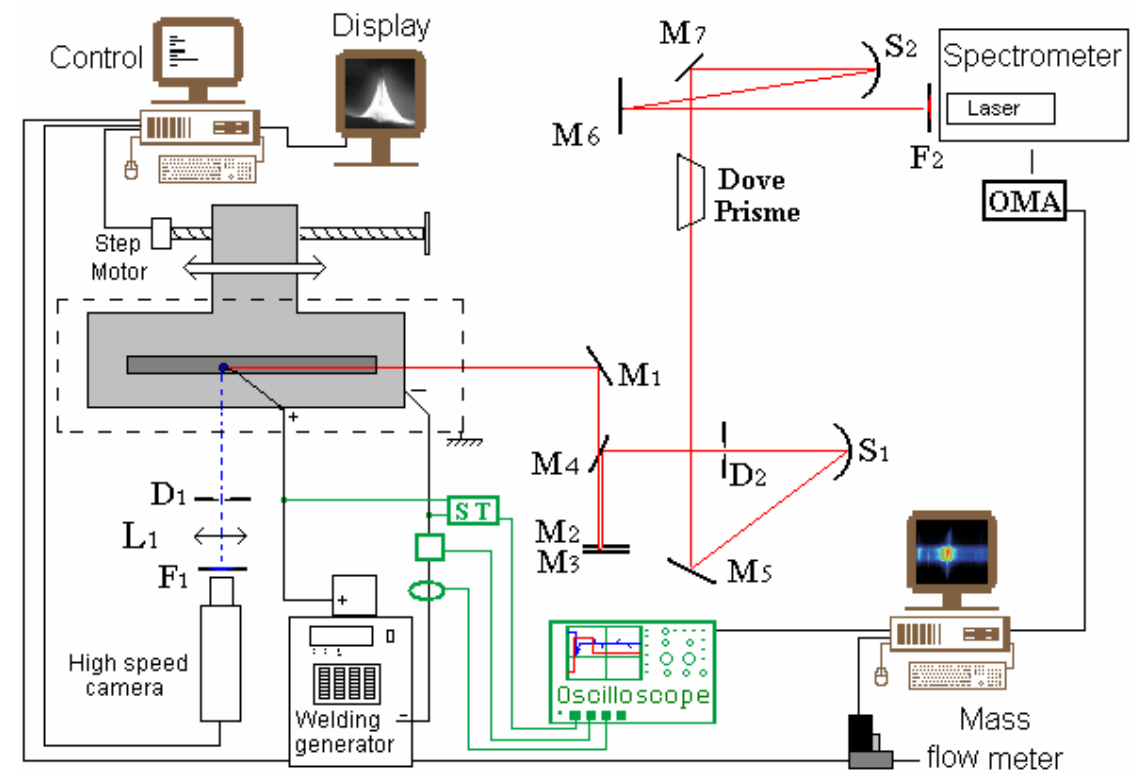

Figure 1. Experimental Arrangement.

A laser was placed at the output of the spectrometer, so the backward beam indicates the optical path. By placing an object where the plasma will burn it was possible to visualize the slice of the plasma 
that would be observed. The targeted height was estimated by observing the position of the laser spot on the consumable wire, before the welding experiment. For each position, close-up photographs were made to get highest possible precision on the height determination. The scale of the pictures was obtained using precisely known dimensions, such as the consumable wire or the nozzle diameter. With an optical setup magnification of 0.4 and a spectrometer slit width of $40 \mu \mathrm{m}$, the imaged plasma slice had a thickness of $100 \mu \mathrm{m}$. Considering the positioning accuracy, the vertical step was taken equal to $0.5 \mathrm{~mm}$.

The lower part of the plasma can not be observed easily, as the weld bead can extend more than one millimetre above the workpiece. The first imaged height was then taken at $2 \mathrm{~mm}$. On the upper side of the column, the presence of the liquid metal vein streaming from the end of the consumable wire also disturbs the measurement. The diagnostic becomes impossible when its width becomes greater than $0.3 \mathrm{~mm}$, which occurs above $6.5 \mathrm{~mm}$ over the base plate. With these two limits it is possible to get ten vertical positions.

In addition to the spectroscopic diagnostic, the shape of the plasma was recorded using a high-speed video camera with a strong magnification. Data were acquired at 3000 frames per second (fps) with a spatial resolution in both directions of $10 \mu \mathrm{m}$, to get detailed information on the plasma central part and the electrodes configuration. Additional experiments were made at $5000 \mathrm{fps}$ with a lower resolution, about $25 \mu \mathrm{m}$ for one pixel, to follow more precisely the plasma shape evolution. In order to get an indication on the metal vapours repartition, the camera was fitted with an interferential filter centred at $468.8 \mathrm{~nm}$ ( $3 \mathrm{~nm}$ fwhm). In this wavelength window, only metal lines can be observed, such as iron or manganese, and the argon continuum can be considered as proportional to the square electron density. The pictures obtained can then give information not only on the plasma components reparation but also on the current flow geometry.

For all experiments, the arc electrical parameters were recorded using differential voltage and current (Hall effect transducer) probes. The data were stored using a numerical oscilloscope and then transferred to a computer, which allows checking if two different experiments conduced with the same input parameters led actually to comparable results. It also allowed discarding data corresponding to transient phenomenon or unwanted instabilities.

\section{Results}

\subsection{Plasma imaging}

The pictures obtained with the blue filter show clearly two different areas in the plasma, as seen in Figure 2. The inner one appears bright, which indicates a stronger iron vapour concentration. Its boundaries are well defined with a cone shape with curved edges, the tip of the cone being attached to the end of the consumable electrode. The outer one appears far less intense and its external limits are blurred. Its overall shape is also conical but wraps the end of the anode wire up to the non-melted part of the electrode.

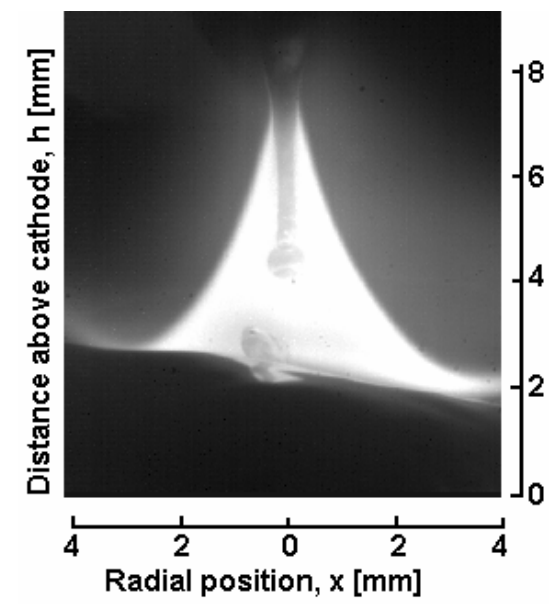

Figure 2. Plasma shape under pure argon at 330 amperes. Picture recorded at $5000 \mathrm{fps}$. 
The streaming vein of liquid metal can be seen on the arc axis. Measurement made on high-resolution pictures allowed estimating its diameter at $0.36 \mathrm{~mm}$. The droplets detach at its extremity between 4 and $4.5 \mathrm{~mm}$ above the base plate reference position. Some pinches can be observed on the liquid metal vein. They first appear $6.5 \mathrm{~mm}$ above the plate and propagate downwards. Two pinches are often present at the same time, separated by about $1.5 \mathrm{~mm}$. Even if with these working conditions the arc remains stable, the geometric configuration is not constant. Concerning the plasma, the bright zone can shrinks or extends with amplitude of more than one millimeter in diameter on the lowest part of the arc. The largest diameters seam to correspond to the times when droplets impact the weld bead. Concerning the metal vein, droplets can sometime detach one millimeter below or above the mean height.

For each height, the radial position of the bright area limit has been estimated. Results are reported in Table 2. The most important radius variations are observed on the lowest part of the column.

\begin{tabular}{ccc}
\hline $\begin{array}{c}\text { Height } \\
(\mathrm{mm})\end{array}$ & Radius $(\mathrm{mm})$ & $\begin{array}{c}\text { Uncertainty } \\
(\mathrm{mm})\end{array}$ \\
\hline 2.0 & 3.57 & 0.43 \\
2.5 & 2.68 & 0.54 \\
3.0 & 1.99 & 0.11 \\
3.5 & 1.72 & 0.09 \\
4.0 & 1.44 & 0.05 \\
4.5 & 1.20 & 0.02 \\
5.0 & 0.95 & 0.02 \\
5.5 & 0.73 & 0.07 \\
6.0 & 0.54 & 0.05 \\
6.5 & 0.37 & 0.05 \\
\hline
\end{tabular}

Table 2. Radius of the central part of the plasma.

\subsection{LTE hypothesis validation}

The first step for excitation temperature calculation is the calculation of calibrated emission coefficients for the three iron lines. The radial profile of the $538.3 \mathrm{~nm}$ iron line, at $5.5 \mathrm{~mm}$ above the cathode, is given in Figure 3a. Then the Boltzmann graphs are plotted for each radial position, as shown in Figure $3 \mathrm{~b}$ for a radius of $0.84 \mathrm{~mm}$ at $5.5 \mathrm{~mm}$ above the cathode.

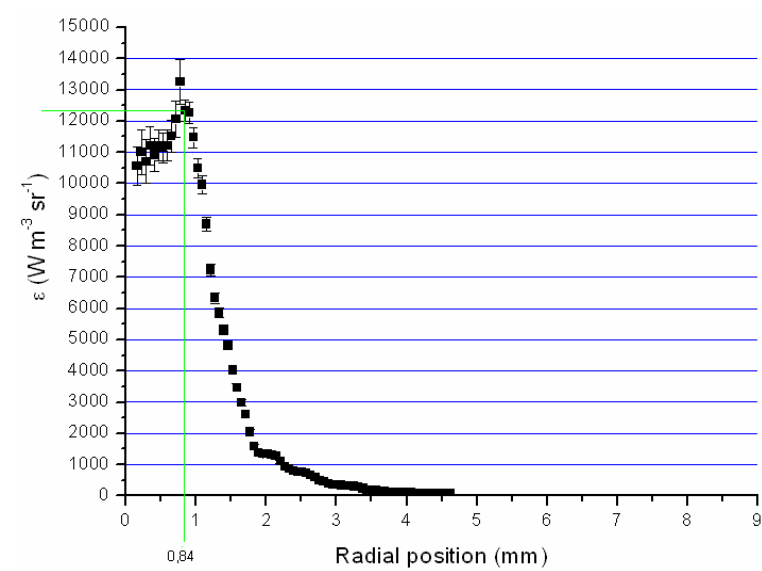

a/ Emissivity of the $538.3 \mathrm{~nm}$ iron line

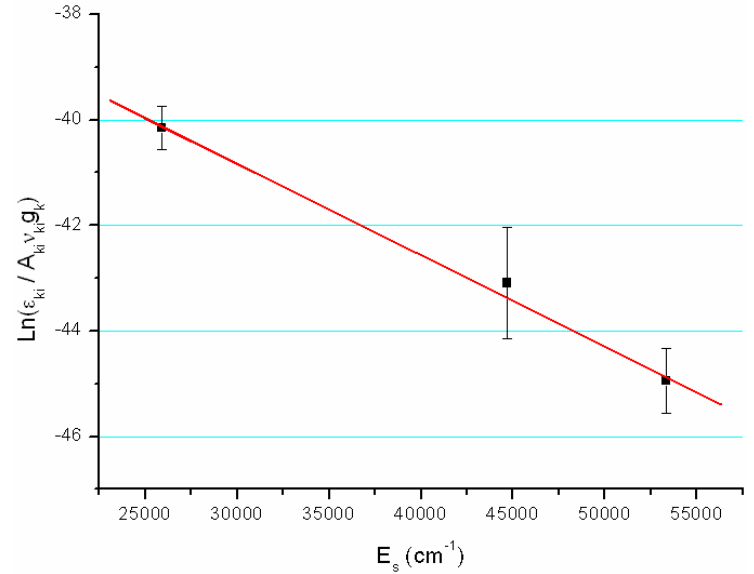

b/ Boltzmann plot : $r=0.84 \mathrm{~mm}$

Figure 3. Intermediary results for excitation temperature calculation - argon, $I=330 \mathrm{~A}-h=5.5 \mathrm{~mm}$.

An automatic procedure allows to obtain a file containing excitation temperature as a function of radial position. It is then plotted on the same graph with the electron temperature, as seen in Figure 4 for the position $5.5 \mathrm{~mm}$ above the base metal. The agreement of the two temperatures is estimated taking into account the uncertainties of both methods, where the error bars of the two curves overlap. For these position only the metal vapour concentration is calculated, assuming the plasma is in LTE. On the 
example shown in Figure 4, the two curves best fit for radial position between 0.5 and $3 \mathrm{~mm}$, but taking into account the error bars the LTE validity can be assumed on the entire presented range. This case is well representative of the various studied heights, for which this validation procedure is always used. Even when the temperature can be calculated for greater radius, especially in the lower part of the column, the area where the two temperatures match never exceeds the limit of $4 \mathrm{or} 5 \mathrm{~mm}$. In some case the central part of the plasma has also to be discarded for the metal vapour concentration calculations. More detailed analysis of this method for LTE validation is presented in [18].

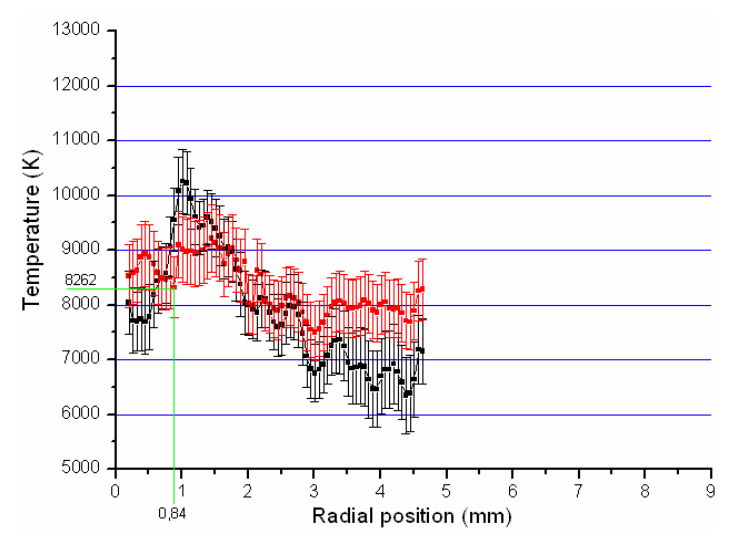

Figure 4. Electron temperature at $5.5 \mathrm{~mm}-\operatorname{argon}, I=330 \mathrm{~A}$

[- Sola method; • Boltzmann plot method].

\subsection{Plasma electron temperature and density}

For each measured height, the best spectra were selected for parameters calculation. Then the data were averaged to improve the noise signal ratio. While separate curves were obtained for the ten vertical positions, it has been chosen to plot comparable results on the same graph. For electron temperature and density, three parts of the plasma are identified: the lower part, ranging from 2 to $3.5 \mathrm{~mm}$; the medium part, ranging from 4 to $5.5 \mathrm{~mm}$ and the upper part corresponding to 6 and $6.5 \mathrm{~mm}$.
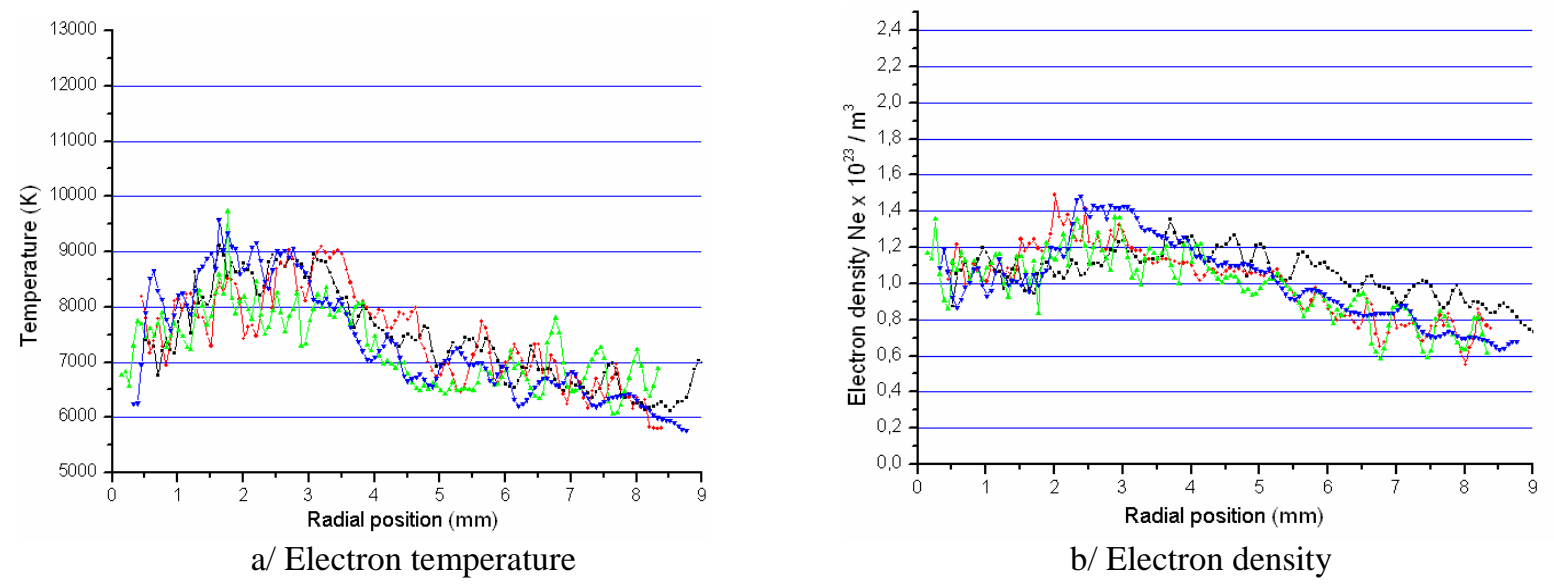

Figure 5. Plasma diagnostic from 2 to $3.5 \mathrm{~mm}-\operatorname{argon}, I=330 \mathrm{~A}$. [ $h=2.0 \mathrm{~mm} ; \bullet h=2.5 \mathrm{~mm} ; \Delta h=3.0 \mathrm{~mm} ; \nabla h=3.5 \mathrm{~mm}]$

\subsubsection{The lower part of the plasma.}

Close to the base plate, constituting the cathode, a maximal temperature of $9000 \mathrm{~K}$ is observed at a radius of 2 to $3 \mathrm{~mm}$ as seen in Figure 5a. The temperature decreases continuously with radius to a limit of about $6000 \mathrm{~K}$. Data can be measured up to $9 \mathrm{~mm}$ from the axis. Temperature also decreases in the central part of the column, the lowest value being about $7000 \mathrm{~K}$. There is no major difference between the four considered heights, even if for the upper ones, at 3 and $3.5 \mathrm{~mm}$ the maximum seems closer to the arc axis. 
The electron density follows a comparable evolution as seen in Figure 5b, with a maximum value at $2.5 \mathrm{~mm}$ away from the axis, a constant decrease towards the periphery and, in a smaller proportion, on the arc axis. The density ranges from about $8 \times 10^{22} \mathrm{~m}^{-3}$ to $1.4 \times 10^{23} \mathrm{~m}^{-3}$. The value on the axis is about $10^{23} \mathrm{~m}^{-3}$.

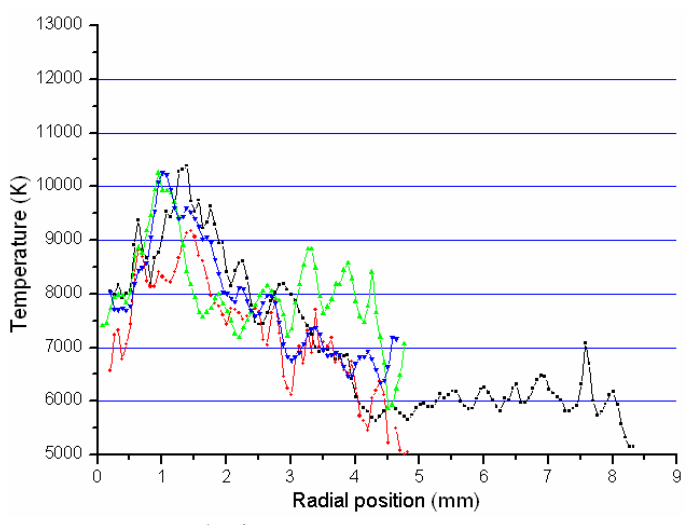

a/ Electron temperature

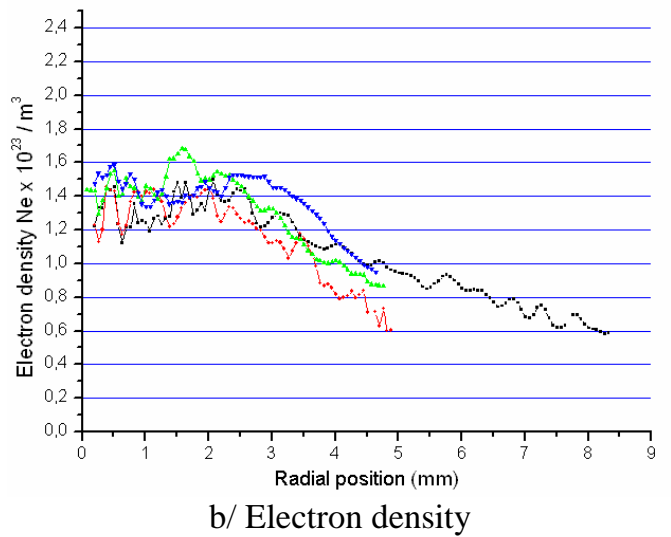

b/ Electron density

Figure 6. Plasma diagnostic from 4 to $5.5 \mathrm{~mm}-\operatorname{argon}, I=330 \mathrm{~A}$.

[ $h=4.0 \mathrm{~mm} ; \bullet h=4.5 \mathrm{~mm} ; \Delta h=5.0 \mathrm{~mm} ; \nabla h=5.5 \mathrm{~mm}]$

\subsubsection{The central part of the column.}

For height between 4 and $5.5 \mathrm{~mm}$ the temperatures curves are sharper, as seen in Figure 6a. If the lower limits remain the same as for the inferior part, with values of $7000 \mathrm{~K}$ on the axis and $6000 \mathrm{~K}$ at the periphery, the maximum rises up to $10500 \mathrm{~K}$. The position of this maximum is also closer to the axis, with a position between 1 and $2 \mathrm{~mm}$.

The electron density also increases with values close to $1.6 \times 10^{23} \mathrm{~m}^{-3}$ as seen in Figure $6 \mathrm{~b}$. However, unlike the lower part of the plasma, in the central part no important decrease can be observed on the axis of the arc. The value at the periphery still remains close to $8 \times 10^{22} \mathrm{~m}^{-3}$.

Except for the plasma slice at $4 \mathrm{~mm}$, the data could not be measured for radius greater to $5 \mathrm{~mm}$. This is due to the cone shape of the plasma, with narrowing dimensions when closing to the positive electrode.
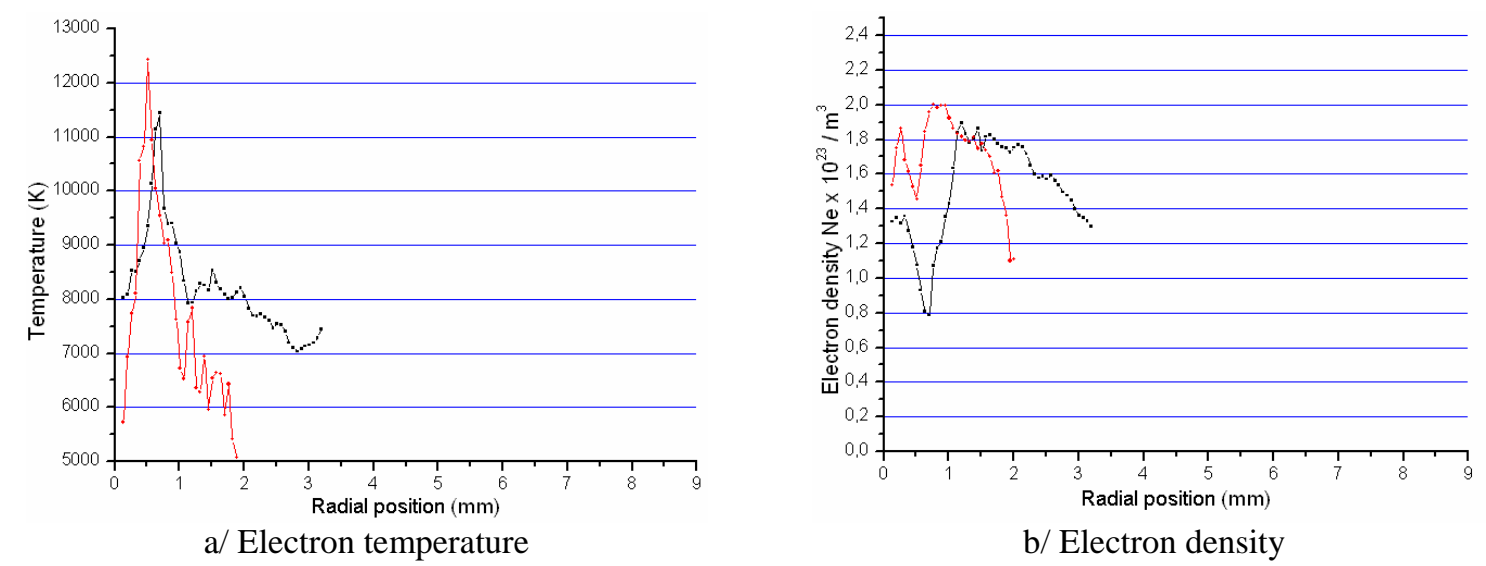

Figure 7. Plasma diagnostic from 6 to $6.5 \mathrm{~mm}-\operatorname{argon}, I=330 \mathrm{~A}$.

[ $h=6.0 \mathrm{~mm} ; \bullet h=6.5 \mathrm{~mm}]$

\subsubsection{The upper part of the column.}

The temperature strongly increases close to the anode, with a maximum value of about $12500 \mathrm{~K}$ at $6.5 \mathrm{~mm}$ above the cathode as seen in Figure 7a. The radial position of the maximum is less than $1 \mathrm{~mm}$. Due to the presence of the liquid metal vein at the central part of the plasma, the temperature cannot be measured properly for radius smaller than $0.5 \mathrm{~mm}$. The decrease on the axis is then only a trend, for 
the curve corresponding to the greatest height. However, at $6 \mathrm{~mm}$ above the base plate this appears clearly, with a temperature reaching almost $12000 \mathrm{~K}$ and dropping close to $9000 \mathrm{~K}$ on the column axis. The temperature on the periphery falls rapidly due to the sharp shape of the plasma cone close to the upper electrode.

The electron density still increases when closing to the anode, with a maximum value slightly above $2 \times 10^{23} \mathrm{~m}^{-3}$ as seen in Figure $7 \mathrm{~b}$. The density seems to decrease on the arc axis, but the strong fall observed for the height at $6 \mathrm{~mm}$ should be interpreted with care.

\subsection{Plasma composition: iron vapours ratio over argon}

The proportion of iron vapours over argon (in atomic percentages) is measured for all positions. The data have also been sorted considering similar behaviour, but four parts rather than three can be identified. The general evolution is a strong increase with height above the base plate. The concentration falls beyond a given radius that decreases when closing to the upper electrode and the maximum values are observed away from the axis.

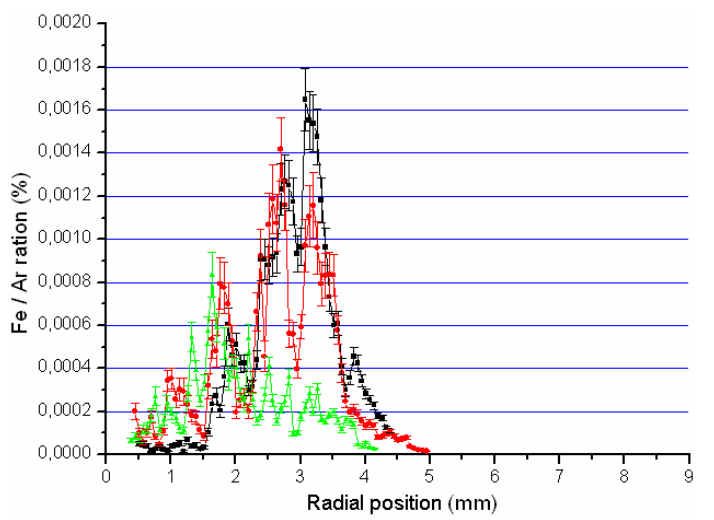

a/ $2 \mathrm{~mm} \leq h \leq 3 \mathrm{~mm}$

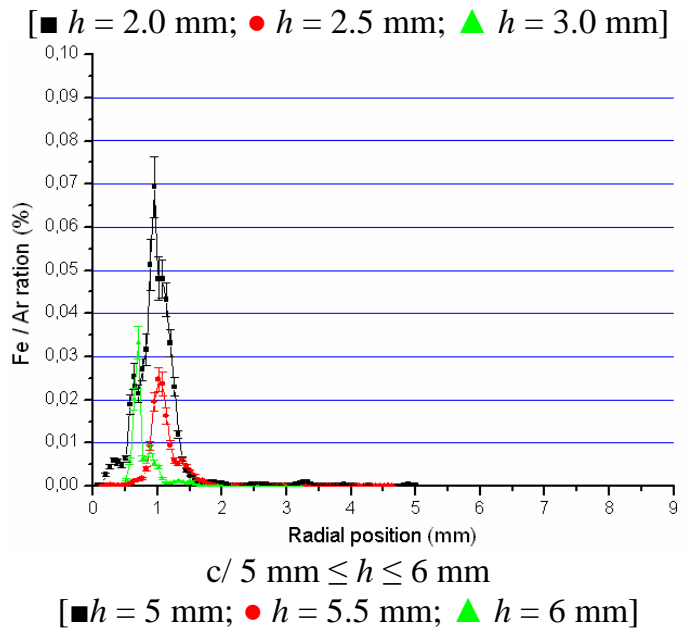

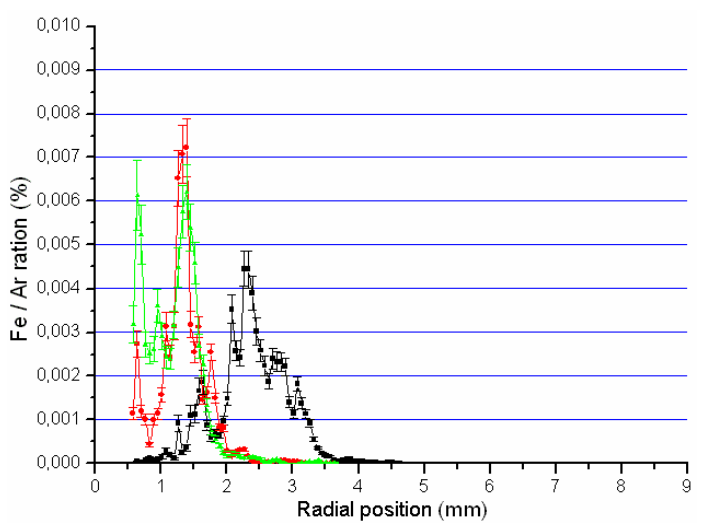

$\mathrm{b} / 3.5 \mathrm{~mm} \leq h \leq 4.5 \mathrm{~mm}$
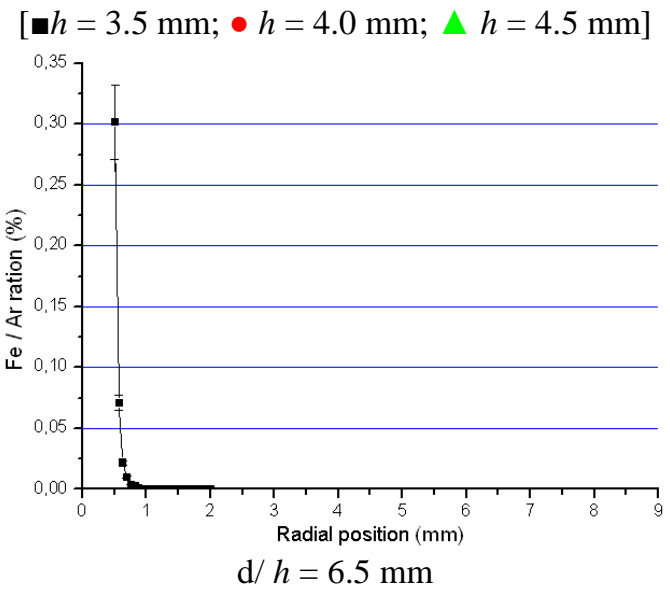

Figure 8. Proportion of iron vapour from 2 to $6.5 \mathrm{~mm}-\operatorname{argon}, I=330 \mathrm{~A}$.

On the lower part of the plasma, the concentration remains less than $0.002 \%$ as seen in Figure $8 \mathrm{a}$. The two lowest slices show greater iron content than what is observed at $3.5 \mathrm{~mm}$. At this position the repartition seems more homogeneous over radius.

For an intermediate position, corresponding to the central part of the arc the concentration is about three times larger but remains below $0.01 \%$ as seen in Figure $8 \mathrm{~b}$. If $3.5 \mathrm{~mm}$ above the cathode, the maximum is observed about $2.5 \mathrm{~mm}$ away from the axis, it gets closer than $2 \mathrm{~mm}$ for the two upper slices.

On the upper part of the plasma, the iron concentration is tenfold increased, with values up to $0.06 \%$ as seen in Figure 8c. The iron content is greater at a height of $5 \mathrm{~mm}$ than for the two upper slices but 
the maximum position still gets closer to the axis when closing to the anode. It is located less than one millimeter away from the axis for the highest vertical position.

Data for the last studied height had to be plotted on a separate graph due to the scale, the maximum concentration being five times larger than for the slice just below. A seen on Figure 8d, the iron content reaches $0.3 \%$ near the anode which is more than hundred times the value observed at the lowest part of the column. On the other hand, the strong concentration area is narrower as it is lo larger than $1 \mathrm{~mm}$ in radius.

\section{Discussion}

Concerning the electron density, while the increase towards the anode follows the evolution observed for temperature, the radial profile does not so clearly. In particular, there is almost no central drop in the middle height of the plasma. According to the LTE hypothesis, the correlation between electron temperature and density would be expected to be stronger. The calculation has been made assuming it was valid, but the two following points must be kept in mind:

- The agreement validity between excitation and electron temperature was limited, due to the uncertainties associated with the Boltzmann plot method. The results only give a supporting evidence for equilibrium.

- The proposed method for LTE validation only checks the excitation equilibrium. Full LTE validation would need Saha equilibrium verification, which will require additional experimental work.

LTE hypothesis is often assumed to be valid in welding plasma studies, even in the case of GMAW plasmas as most parameters determination needs it. The work presented here is based on first experimental investigation of plasma equilibrium state, knowing that complete evidences are still needed.

Concerning the electron temperature, the two main results are the maximum value measured at $12500 \mathrm{~K}$ and the temperature drop of 3000 to $4000 \mathrm{~K}$ on the central part of the column. The maximum temperature is about $10000 \mathrm{~K}$ less than the one calculated by models considering either no metal vapours influence or a constant repartition [5, 6]. However, more recent models that consider an inhomogeneous repartition of metal vapours have been developed. The results have showed a maximum of temperature of about $13000 \mathrm{~K}$ dropping to $10000 \mathrm{~K}$ on the arc axis [19, 20].

The measured iron concentration remains however low, with a maximum value less than $1 \%$ close to the anode, but confirm what had been obtained by S.Zielinska [21]. The analysis of the iron vapours repartition has to be done taking into account the electrodes configuration, especially the presence of the liquid metal vein. It is not present below $4 \mathrm{~mm}$, which corresponds to the lowers measured values while the slight increase at 2 and $2.5 \mathrm{~mm}$ can be explained by the proximity of the weld bead. Over the radial direction, the liquid metal streaming on the plasma axis should lead to high concentration close to the axis, but the dependence between the iron concentration and the temperature seem to be more relevant. The iron concentration indeed drops toward the axis and its maximum value is observed for the highest temperatures. Even at $6.5 \mathrm{~mm}$ above cathode, where concentration is only calculated for radius greater than $0.5 \mathrm{~mm}$, intermediary results seem to indicate a decrease close to the axis. Then it seems that the iron concentration repartition obeys to a balance between the enrichment from the liquid metal vein and its cooling effect. Results from studies in pulsed GMAW with aluminum [22, 23 indicate a metal vapor concentration above $10 \%$, which is more than fifty time larger than what we present here. Both results still might be not incompatible as the physical properties of iron and aluminum strongly differ. This difference would support the importance of the thermodynamic parameters governing the considered metal vaporization and the resulting metal concentration in the plasma. Besides, the arc behaviour differs in pulsed mode, with strong current variation (50 amperes/ $\mu \mathrm{s}$ ) and high current (600 amperes) impulses that are not observed in continuous operation. The results we give are obtained for pure argon.

Thus, all these results seem not corroborate the data obtained by modeling:

- Given the low measured values, the presence of metallic vapors in the plasma column can be neglected. But models based on this assumption $[5,6]$ do not provide temperature decrease on the axis of the column, contrary to what has been achieved here.

- Models that take into account that the metal vapour in the plasma, can foresee the temperature fall 
on the axis of the column $[19,20]$, but with an amount of iron in the plasma by several orders of magnitude higher than those measured in this work.

As supposed in a precedent paper [4] and recently provided by Shnik et al [20], the dominant effect of iron could be due to the strong radiative emission from the metal vapour, inducing a high radiative cooling and a temperature fall of $T_{e}$ on the column axis, but without other strong direct effects on the thermophysical properties of the plasma.

The iron concentration repartition has also to be compared to the data obtained by plasma imaging. It appears that the bright zone seems to correspond indeed to the highest concentration. For example, at 2 $\mathrm{mm}$ above the cathode the concentration drops for a radius greater than $3.5 \mathrm{~mm}$ and vanishes beyond $4.5 \mathrm{~mm}$, while the bright zone limit oscillates between 3 and $4 \mathrm{~mm}$. For the slice $5 \mathrm{~mm}$ above the cathode, the concentration falls for radius greater than $1.4 \mathrm{~mm}$ while the limit observed on the images is about at $1 \mathrm{~mm}$.

The high speed imaging showed evolution of the arc shape, especially the central bright zone, over time. Even if the shape remains stable most of the time, the column diameter close to the base plate can increase and decrease by one millimetre in less than one millisecond. As the exposition time is $50 \mathrm{~ms}$ for spectroscopic measurement, the resulting spectra integrates all variations which can explain the non regular shape of the obtained curves, especially the two peaks observed at $2 \mathrm{~mm}, 2.5 \mathrm{~mm}$ and $4.5 \mathrm{~mm}$ above the cathode.
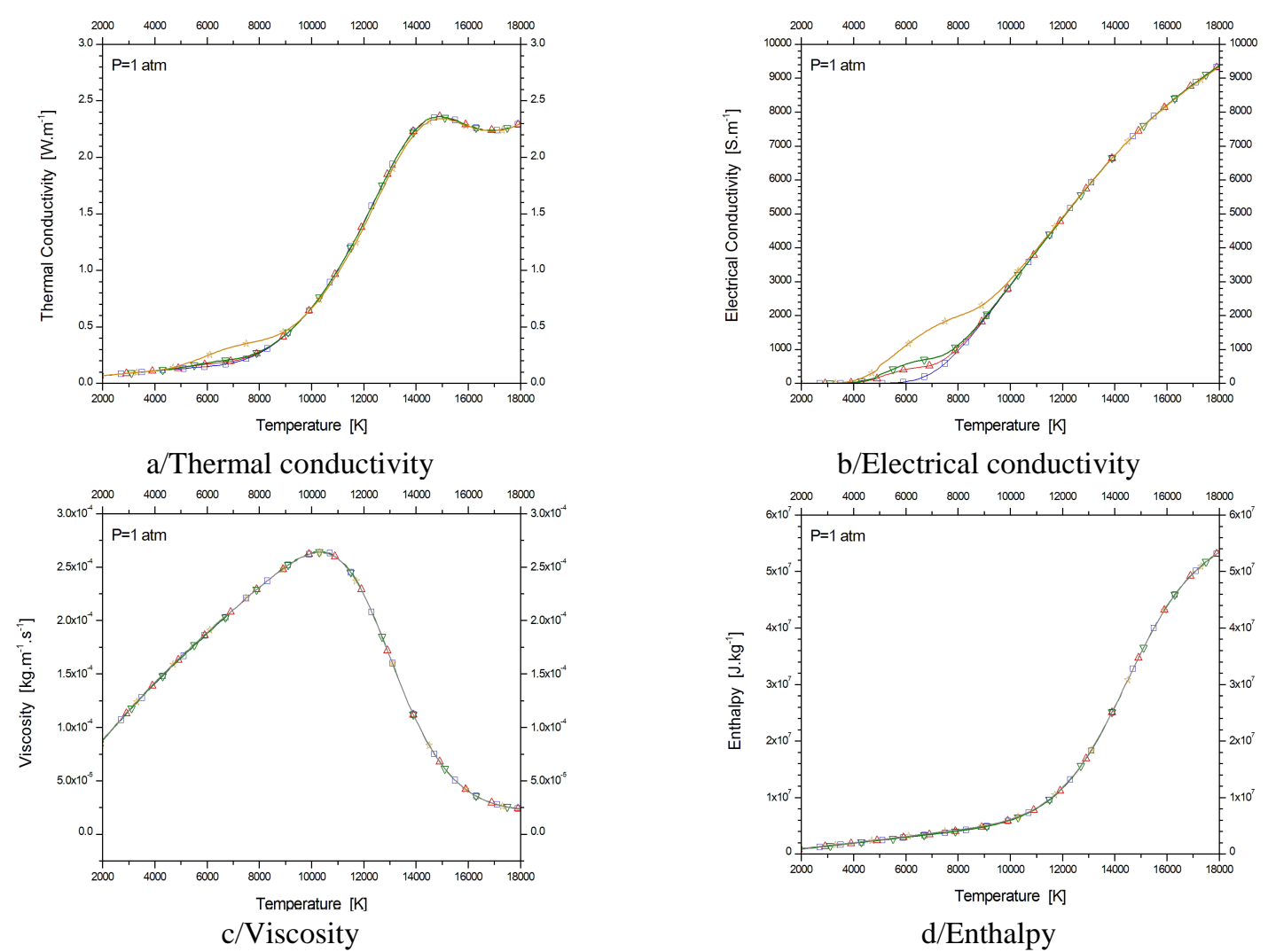

Figure 9. Thermophysical properties temperature dependence of a Ar-Fe plasma in LTE, atmospheric pressure. [ $\square$ Pure argon ; $\triangle 99.95 \% \mathrm{Ar}+0.05 \% \mathrm{Fe} ; \nabla 99.90 \% \mathrm{Ar}+0.10 \% \mathrm{Fe}$; is $99 \% \mathrm{Ar}+1 \% \mathrm{Fe}$ ]

\section{Thermophysical properties of the plasma and possible effects on the metal transfer in the arc}

The thermophysical data calculated by A.B.Murphy [24, 25] for an Ar-Fe plasma in different atomic proportions, show that in the temperature range studied in plasma and for small amounts of $\mathrm{Fe}$ in plasma $(\leq 0.1 \%)$, the metal vapours have a limited effect on the values of plasma viscosity, electrical conductivity, and enthalpy (Cf Figure 9). The effect on its thermal conductivity is also quite weak, except perhaps for temperatures between $4000 \mathrm{~K}$ and $7000 \mathrm{~K}$, so in the periphery of the arc column. 

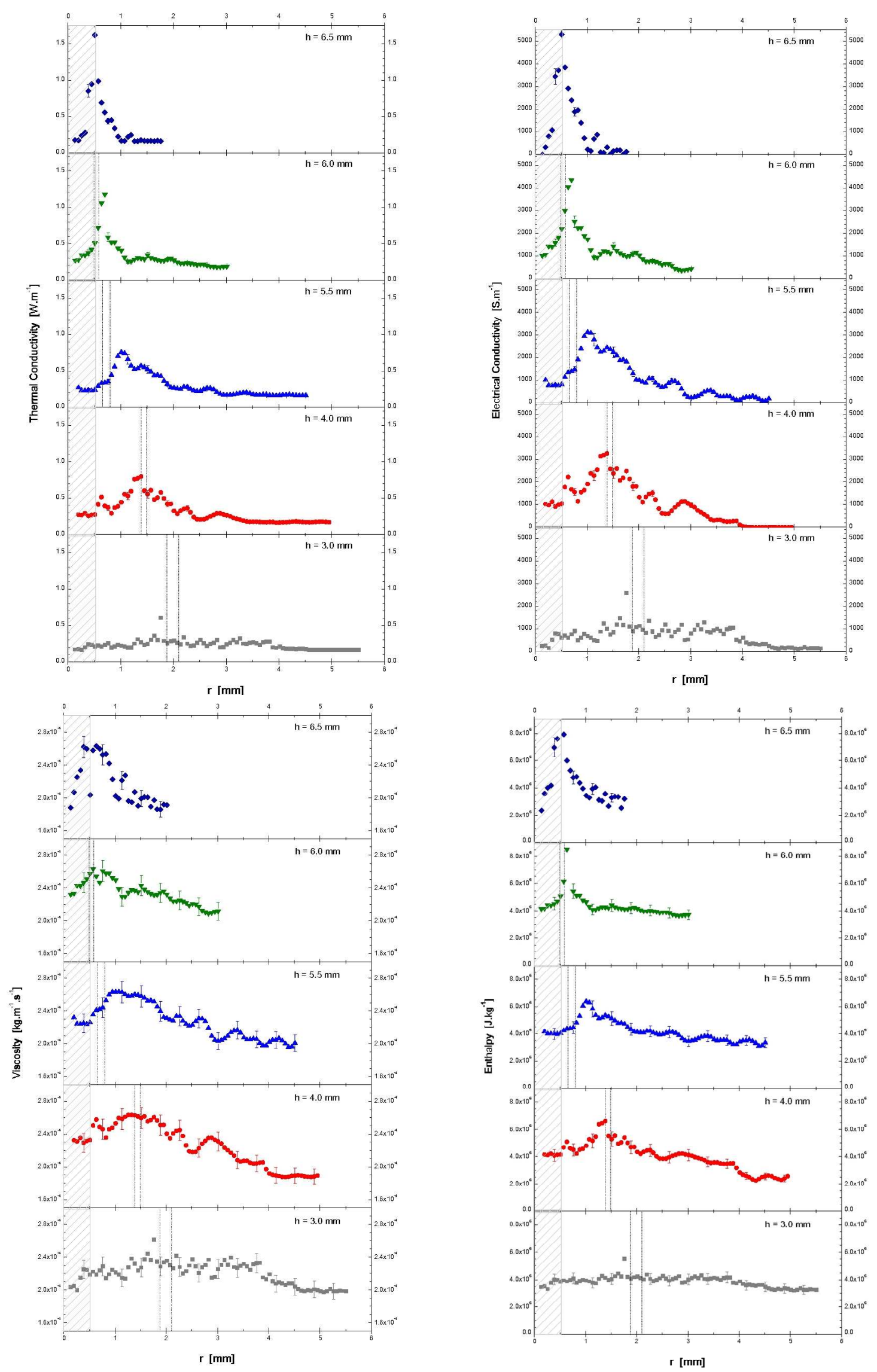

Figure 10. Estimated thermophysical properties in the GMAW plasma column 
In a first approach, it is possible to estimate most of the thermophysical properties of MIG plasma by considering a pure argon plasma in LTE at atmospheric pressure (See Figure 10). On these graphs, we have shown the boundary of the bright area (dotted line, according to Table 2), and have marked the central zone of the arc, corresponding to the radius of the wire anode and the transition metal drops.

- The temperature drop observed at the center of the plasma column, clearly leads to an off-axis maximum of the plasma thermophysical properties, which that disappears close to the workpiece;

- The fall of viscosity observed in the center of the arc column could explain the transfer of metal in the plasma, which is always in a spray mode (small droplets, with axial metal transfer mode) under pure argon: liquid metal is then channeled through "channel" at lower viscosity in the plasma.

First results obtained in metal active gas (MAG) process [4], using gas mixture of argon and carbon dioxyde, seems indicate that the proportion of iron in the plasma column increases with $\mathrm{CO}_{2}$ concentration in the shielding gas $[21,26]$. Then, the viscosity drop in the center of the column disappears and the molten metal can not easily get into the plasma.

In the same time, $\mathrm{CO}_{2}$ presence in the shielding gas favors the formation of an of oxide gangue at the extremity of the wire, by chemical oxidation-reduction reaction [27]. This bad conductor layer hinders the current transfer and the arc needs a larger attachment zone all around the droplet. That explains the modification of arc shape associated to the different regimes [28], but also the increase of the size of the droplet.

These droplets are then ejected out of the axis, and the transfer of metal in the arc evolve to the globular regime [3], not available for the process efficiency.

\section{Conclusion}

The electron temperature and the electron density as well as the iron vapours ratio over argon were calculated with a vertical step of $0.5 \mathrm{~mm}$ and a radial resolution of $62 \mu \mathrm{m}$ for GMAW plasma operating under pure argon, with a current of $330 \mathrm{~A}$. The temperature drop is observed in the main part of the plasma column while the electron density seems to increase toward the axis, especially on the middle of the arc. The calculated temperatures are closer to the numerical results obtained by taking into account the non homogenous repartition of iron vapours. If the measured concentrations remain low, our results showed very strong variation on both the radial direction and the vertical direction.

This work must be continued to study the LTE state in the GMAW plasma in metal active gas (MAG) process, and try to estimate the distribution of relative concentrations in argon and iron, and then the principal transport and thermodynamic characteristics (thermal and electrical conductivity, viscosity...) in the arc column. First results obtained with adjunction of $\mathrm{CO}_{2}$ in shielding gas seem to indicate higher metal vapor concentrations, which confirms the importance of plasma composition on transport properties $[21,26]$.

\section{Acknowledgments}

This work was supported in part by Air Liquide, Saint Ouen l'Aumone (France), and by the Integrated Action Project Polonium 958055E.

\section{References}

[1] Lesnewich B A, 1958 Welding. Journal. 37, 343s

[2] Lesnewich B A, 1958 Welding. Journal. 37, 418s.

[3] Lancaster J F, 1984. The Physics of Welding. Pergamon Press, Oxford, pp. 204-234.

[4] Zielinska S, Musioł K, Dzierzega K, Pellerin S, Valensi F, de Izarra C and Briand F, 2007, Plasma Sources Sci. Technol. 16 pp.832-838

[5] Haidar J and Lowke J J, 1996 J. Phys. D 29 p2951

[6] Haidar J, "A theoretical model for gas metal arc welding and gas tungsten arc welding", 1998, J. Appl. Phys 84 p3518

[7] Sola A, Gamero A, Cortino J, Saez M, Lao C, Calzada M D, Quintero M C and Ballesteros J, 1991, ICPIG XX Barga (Italy, 5-12 July 1991) Book of Contributed Papers p.1147 
[8] Torres J, Jonkers J, van de Sande M. J, van der Mullen J. J. A. M, Gamero A and Sola A, J. Phys. D 2003 36, pp55-59

[9] Lesage A, Lebrun J L and Richou J, 1990, Astrophys. J. 360 pp737-740

[10] Konjevic N,Lesage A, Fuhr J R and Wiese W L, 2002, J.Phys.Chem.Ref.Data 31

[11] Pellerin S, Musiol K, Pokrzywka B and Chapelle J, 1996, J.Phys.B 29 pp3911-3924

[12] Nowak S, van Lammeren A C A P and van der Mullen J A M, 1987, ISPC 8 Tokyo, P-027, pp398-403

[13] Crosswhite H M, 1975 J. Res. NBS (U.S.) 79a, 17. NIST Atomic Spectra Database, http://physics.nist.gov/asd3

[14] Norlen G, 1973, Phys. Scr. 8, p249. NIST Atomic Spectra Database, http://physics.nist.gov/asd3

[15] S.Pellerin, 1994 Thèse de l'Université d'Orléans, France

[16] Halenka J and Grabowski B, 1984, "Atomic partition function for iron", Astron. Astrophys. Suppl. Ser. 57 pp.43- 49

[17] Halenka J and Grabowski B, 1977, "Remarks on atomic partition function, the example of tin", Astron. Astrophys. $\mathbf{5 4}$ pp.757-764

[18] F.Valensi, S.Pellerin, A.Boutaghane, K.Dzierzega, N.Pellerin and F.Briand, "LTE Experimental validation in a GMAW plasma column", Contributions to Plasma Physics (in press) 2010

[19] Schnick M, Füssel U, Hertel M, Spille-Kohoff A and Murphy A B, O2.12 - 19th International Symposium on Plamsa Chemistry, Bochum, July 26-31 (2009)

[20] Schnick M, Füssel U, Hertel M, Spille-Kohoff A and Murphy A B, « Metal vapour causes a central minimumin arc temperature in gas-metal arc welding through increased radiative emission », 2010, J. Phys. D 43-2 p.022001

[21] Zielinska S, «Propriétés physiques du plasma MIG-MAG», 2005, PhD Thesis, University of Orléans (France) and Jagielonian University of Cracow (Poland) (in french or polish languages)

[22] Goecke S-F, «Auswikkungen von Aktivgaszumischungen im vpm-Bereich zu Argon auf das MIG Impulsschweissen von Aluminium », 2004, PhD thesis - Fakultät V - Verkehrs- und Maschinensysteme der Technischen Universität Berlin (in german language)

[23] Goecke S-F, Metzke E, Spille-Kohoff A and Langula M, «ChopArc - MSG-Lichtbogenschweißen für den Ultraleichtbau », 2005, bmb+f-gefördertes Verbundprojekt, Fraunhofer IRB Verlag, ISBN 3-8167-6766-4 (in german language)

[24] Murphy A B and Arundell C J, "Transport coefficients of argon, nitrogen, oxygen, argon-nitrogen, and argon-oxygen plasmas", 1994, Plasma Chem. Plasma. Process. 14 pp.451-490

[25] Murphy A B, «The effects of metal vapour in arc welding », 2010 J. Phys. D: Appl. Phys. 43 (this issue)

[26] Valensi F, «Contribution à l'étude des ph'enomènes liés aux effets anodiques et cathodiques en soudage MIG-MAG », 2007, PhD Thesis, University of Orléans (France) (in french language)

[27] Zielinska S, Valensi F, Pellerin N, Pellerin S, Musiol k, de Izarra Ch and Briand F, « Microstructural analysis of the anode in gas metal arc welding », 2009, Journal of Materials Processing Technology 209 pp. 3581-3591

[28] Zielinska S, Pellerin S, Valensi F, Dzierzega K, Musiol K, de Izarra Ch and F.Briand, « Gas influence on the arc shape in MIG-MAG welding », 2008, Eur.Phys.J. Appl.Phys. 43-1 pp.111-122 